\title{
Research of the Use of Professional Teaching Strategies in Vocational Colleges
}

\author{
Jiuchao $\mathrm{Li}^{1, \mathrm{a}^{*}}$, Zhao Yao, ${ }^{1, \mathrm{~b}}$ and Zhao Jin ${ }^{1, \mathrm{c}}$ \\ ${ }^{1}$ No.1, Huayuan Road, Changchun City, Jilin Prov. China 130117 \\ a247658766@qq.com, byaozhao_1979@126.com, c781693564@qq.com
}

Keywords: Vocational Colleges; Professional; Teaching Strategies

\begin{abstract}
Formulating teaching strategies is an important part of talent training. Because there are many differences between the professional and repair majors, this paper mainly discusses the problems related to the application of professional teaching strategies in the colleges and universities, and explores the problem of providing service guarantees by using the informational teaching network platform as an example.
\end{abstract}

\section{Introduction}

The application of majors in vocational colleges is a new type of specialty after the reform, and it belongs to the new professional after the reform, and it has a big difference with the traditional repair profession in our school. In terms of teaching principles and concepts, the application of professional and traditional majors is the same in the vocational colleges, but the traditional professional teaching strategies are not completely suitable for the professional colleges and universities. The same is true for the online teaching platforms that support the teaching strategies. Many of the colleges and universities only simply modified and revised the original professional teaching strategies and network platforms and applied them to the applied majors. As a result, the professional teaching activities of the incumbent colleges could not be properly integrated with the times and the future. The faculty organizes the teaching activities in the form, the students can not accurately locate themselves in the process of learning, and the final teaching effect can not be reasonably evaluated. Of course, in these links, there are also objective reasons why the network technical conditions cannot meet the teaching needs.

This article mainly takes the course taught by the author as an example, discusses the professional teaching strategies of the colleges and universities, and discusses the construction of the digital media teaching network platform that meets the needs of the teaching strategies under the information network technology. Hope and the majority of the hospitals The school uses professional faculty to fully communicate and make progress together.

\section{Research on the Essential Factors of Applying Professional Teaching Strategies Based on Positions}

The so-called teaching strategy refers to the overall considerations including the teaching activity procedures, teaching methods, teaching forms and teaching media to achieve specific teaching objectives. The formulation of teaching strategies must meet the following requirements: "Starting from the learning objectives: not contradicting the theory of learning and teaching theory: in line with the characteristics of learning content: suitable for the characteristics of teaching objects: considering the possibility and feasibility of teaching conditions." The formulation of teaching strategies has the following basic characteristics: the selection or formulation of teaching strategies must comprehensively consider the elements of teaching content, media, organizational forms, methods, steps and techniques; the teaching strategy is not an abstract teaching principle. It is not a teaching mode under the guidance of certain teaching ideas, but a program that can be used by teachers and students to refer to execution or operation in teaching. There is a clear and specific content of "operability"; teaching strategies are based on different teaching objectives and tasks. With reference to the initial state of the students, select the most appropriate teaching content, 
teaching media, teaching organization, teaching methods and combine them to ensure the effective implementation of the teaching process, in order to achieve the characteristics of the teaching objectives, to complete the specific teaching tasks. flexibility".

On the basis of the above principles of teaching strategy formulation, the formulation of professional teaching strategies in vocational colleges emphasizes the following elements:

Creativity and Personalization. The professional use of colleges and universities is aimed at cultivating equipment-use and operational talents, and can adapt to new equipment use, fault judgment, and emergency disposal. These positions require not only skilled operation skills, but also students with sufficient creativity and personalization. It is difficult for people who have smoothed their minds to adapt to their work requirements and their development potential is limited.

The Collision of Thinking. In the application of professional courses in vocational colleges, a sufficient and reasonable collision of thoughts between the instructors and the students is a must. In the absence of a collision of thoughts, the entire classroom is boring because of the loss of spirituality. On the surface, the teacher taught seriously and the students learned seriously, but actually lost the most important things, which is contrary to element 1.

Modernization and Intelligence. The use of professional is a professional discipline closely related to the operation of equipment. Therefore, the teaching of professional courses should be not only in line with the content of practice, but also in form. This not only concentrates students' attention, but also enhances students' perceptions of their majors, thereby enhancing their interest in learning.

The Balance between Autonomy and Team. self-directed learning can maximize the learning outcomes of students. Team learning can enhance the spirit of collaboration among students. The use of professionalism requires teamwork.

\section{More Suitable for Applying Professional Teaching Strategies in Vocational Colleges}

The teaching strategies adopted by the colleges and universities advocated in this paper are mainly considered in the following aspects:

The Establishment of Talent Training Goals. As mentioned above, the positions that can be used by professionals are very extensive, but the overall time of teaching is limited. It is not possible to cultivate all-round students, but it should be formulated in combination with the talent training programs and curriculum implementation plans of the institutions. Meet the future needs of the students. The use of professional talents training objectives closely combines talent development trends and needs, emphasizing the use of professional integration and cooperation, and the goal of talent training is also targeted at the corresponding employment positions.

Presentation of positions. The presentation of positions should be based on the teacher-led, student-oriented dual-master mode, highlighting its activities, life, and authenticity. In this session, it is recommended to adopt "inquiry-based learning": First, in the preparation stage of teaching, the instructor needs to confirm the learning content objectives and the students' practical thinking ability, and prepare questions according to the student's post background. This stage requires the instructor to conduct practical job research and grasp the students' past learning. It is more difficult at this stage of the low school year. Then in the teaching phase, teachers and students need to change their identities, not just the textbook examples. The final post-teaching evaluation stage, because most of the professional courses can not use the traditional test paper assessment, the faculty must be reasonable, multi-faceted evaluation, to explore the flash point of the students.

Basic Learning. A major feature of the professional curriculum is that the "cross-professional" situation is very serious, and the classroom teaching time is limited. In addition to the necessary knowledge, this section recommends "self-learning".

Self-directed learning requires students to "learn, want to learn, to study, to be able to adhere to learning, and to learn". Therefore, teachers should adopt methods that promote students' self-directed learning, stimulate students' intrinsic motivation, focus on learning strategy teaching, and guide students to Learn to monitor yourself. The faculty can't take the simple "demonstration-exercise-demonstration" boring cycle, which can be supplemented by the 
requirement that students take pictures of themselves and read photos after photography, so that students can really solidify the foundation of the course. Moreover, through the learning process of these knowledge, students can also have a clear understanding of their abilities and find their correct position in the follow-up teamwork.

Teaching Guarantee. As a strong support for teaching strategies, it is recommended that in-service colleges and universities combine information network technology to innovate the network platform, develop mobile platforms in a planned manner, and continuously enrich the teaching media to make the work in each link more convenient and easier to implement. Poor sex and ruined food.

\section{Conclusion}

The use of majors in vocational colleges is different from that of traditional colleges and universities. It has many unique elements and characteristics. Therefore, it is necessary not only to establish the goal of using professional talents in the employment of colleges and universities, but also to apply professional education strategies in the colleges and universities. It must also be adapted to local conditions, from time to time, and from place to case. The construction of a good information network platform can make the teaching strategy perfect. This article only makes some thoughts on the application of professional teaching and network platform in practical colleges and universities, and hopes to contribute to the rational, benign and sustainable development of digital media technology talents.

\section{References}

[1] Z.J. Zhou: Caseteaching Research (East China Normal University Press, China 2000), p.20-25.

[2] L. Jin and Y.P Yao: Computer CD Software and Application, 19 (2012), p.199-200.

[3] Liu Hui. Design and Implementation of Maintainability Analysis System Based on Virtual Maintenance Simulation [J]. (2009) 80, p.22-45.

[4] Li Wenjie. Open learning [J] for higher education learning curriculum; vocational and technical education, (2011) 19, p.33-35.

[5] Meng Su Gang .the formation and development of the military talent quality; [J]; Henan; Henan University press, (2001) 5, p.189-193.

[6] Hu Xiaofeng. US Army Training Simulation (2009) 12, p.121-124. 